\title{
Archaeology and Geophysics: Invincible Couple
}

\author{
Mohamed A Rashed* \\ Water Research Center, King Abdulaziz University, Saudi Arabia \\ *Corresponding author: Mohamed A Rashed, Water Research Center, King Abdulaziz University, Jeddah, 21589, Saudi Arabia \\ Submission: 非 October 28, 2017; Published: 眥 December 11, 2017
}

\begin{abstract}
Today, there is almost no new archaeological discovery in which geophysical investigation tools do not play a key role. In fact, looking onto the past century, one could argue that geophysics, in a way, has rescued archaeology and revived it from its old-style techniques involving hard labor and timeconsuming digging and trenching. Today, thanks to geophysics, archaeology utilizes state-of the-art technologies, takes advantage of the most recent data management and processing techniques, and benefits from the latest image processing protocols. However, archaeology is not the only beneficiary from this successful coupling between archaeology and geophysics. Many of the advances in shallow and high-resolution geophysical techniques as well as data processing and interpretation capabilities can be indirectly attributed to the needs, demands and feedbacks of archaeologists. This successful exchange of benefits has resulted in a new scientific term that is commonly used nowadays; that is Archaeogeophysics or Archaeological Geophysics.
\end{abstract}

\section{Introduction}

The reasons behind the growing application of geophysical tools in the field of archaeology are numerous. One of these reasons is that geophysics provides an efficient tool to cover large areas of archaeological interest with little effort, in brief time, and with high precision. Most geophysical instruments used in archaeological investigations today are portable and data collection speed is limited only by how fast a man can walk. Integration of recent technologies such as GPS and remote communication devices into geophysical instruments makes geophysical data acquisition even easier and faster. Such high-speed geophysical investigations become even more vital when investigation time is limited, as in the case of archaeological reconnaissance of an area before implementing new development plans. Moreover, since geophysics is one of the sciences that benefit the most from the increasing computation power and capabilities, this reflects on the high precision and dense data coverage required for archaeological investigations. Moreover, because different geophysical methods probe different physical properties of soil, the vast diversity of geophysical methods available today makes it possible to investigate wide variety of archaeological sites and objects. Integration of more than one geophysical tool to study archaeological sites is proven to be highly effective in diverse types of archaeological investigations [1-3]. Geophysical tools are not only used to investigate new archaeological sites, but they can also be used to study existing sites in order to image detailed structures and objects inside well-known sites. A good example is the geophysical investigations of the of the famous Giza plateau hosting the Pyramids and Sphinx in Egypt [4]. The most important advantage of archaeogeophysics, however, is its noninvasiveness or its capability to investigate delicate archaeological sites with minimal or no damage to its valuable contents. This advantage alone is enough to create such a strong bond between geophysics and archaeology since noninvasiveness is what archaeology needs the most.

The first form of coupling between archaeology and geophysics started about a century ago with the use of aerial photography in archaeological studies after the World War I. Arial photography provided useful information about the surface soil's color, texture, and composition, indicating probable sites of buried artifacts. By the end of the World War II, electric resistivity was extensively used in most archaeological investigations. Magnetic methods started being used in the 1950's and is still used extensively until today in almost all archaeogeophysical surveys. The boom of archaeologygeophysics coupling, however, occurred in the mid 1980's with the emergence of compact geophysical devices capable of providing high-resolution images at high speed such as electromagnetic induction devices, commonly called terrain conductivity meters and ground penetrating radar. Today, archaeology and geophysics seem inseparable and they contribute to each other in a positive way as no other two branches of science do.

Magnetic method was first used in archaeological studies in the late 1950's and is still used in archaeology more frequently than any other geophysical method [5]. This is partly because magnetometers are compact and easy to operate and because magnetic data can be easily processed and interpreted by non-geophysicists. The main reason for the frequent use of magnetic method, however, is 
its unique capability to detect various archeological features [6]. In addition to detecting buried metallic objects, magnetometers can be used to detect disturbed soil, artificially compacted soils, raw bricks, campfire spots, as well as walls and floors of kilns and hearths. Magnetic gradiometers also provide useful geophysical imaging of different archaeological sites.

Electromagnetic induction devices, commonly known as terrain conductivity meters, are portable, compact, and effective devices for archaeological investigations. Because both subsurface apparent electric conductivity and magnetic susceptibility can be mathematically driven from their multi-frequency measurements, terrain conductivity meters provide the most efficient tools for archaeological site investigations [7-10]. Terrain conductivity meters can be used for detecting caves, voids, shafts, walls, ditches, and iron workings.

Five decades ago, the electric resistivity method formed the cornerstone of archaeogeophysical investigations [11,12]. Today, the use of this method faded away for the less invasive and more efficient geophysical tools such as ground penetrating radar (GPR). Recent years have witnessed an increasing use of GPR in different archaeological applications all over the world [Watters, 2004] [9,1316]. Ground penetrating radar provides high-resolution threedimensional images in reasonable time but at relatively high-cost. The cost of GPR data acquisition systems and processing software is falling drastically in recent years, thanks to technological advances and the creators of open-source GPR processing and interpretation software.

Some geophysical methods are rarely used in archaeological investigations, either because of their heavy data acquisition procedures or because they don't always provide clear images of buried archaeological objects. These methods include the radiometric method [17], the gravity method [18], and the seismic method $[19,20]$. In certain conditions, some of these methods are the only suitable tool for archaeological investigations.

There are several obstacles dragging the coupling between archaeology and geophysics, such as the high cost of some geophysical instruments and the complex mathematics and physics needed to fully understand and be able to process and interpret geophysical data. However, the most frustrating obstacle facing the implementation of geophysical investigation tools in every archaeological study is the inherent non-uniqueness of geophysical anomalies, a condition that is always hard to explain to nongeophysicists. This is that the same geophysical anomaly can be caused by different subsurface conditions. This kind of uncertainty about the nature, size and depth causing specific geophysical anomaly is hard to comprehend by archaeologist whose strategy was always excavating and seeing with their own eyes. Another obstacle is related to the lack of contrast between the object of interest and the surrounding environment and the high noise level encountered in some archaeological sites. These obstacles, however, are diminishing rapidly in recent years because of the increasing capabilities of geophysical instrument, the application of integrated geophysical surveys, and the technological advances introduced everyday into geophysical instrumentation and data processing techniques.

Despite of these limitations and obstacles facing the coupling between geophysics and archaeology, the future is expected to carry even more interaction between them. The fact that geophysics can provide tremendous amounts of information about archaeological sites while leaving these sites intact for future archaeologists is the driving force for even stronger coupling between geophysics and archaeology in the future. Moreover, the huge technological advances in the capabilities of geophysical sensors are expected to satisfy the demands made by archaeology in the future. For example, quad rotor-borne geophysics is an emerging branch of geophysics that is specifically perfect for investigating large archaeological sites that are too fragile to be investigated using heavy ground geophysical tools. Moreover, the increasing data storage capacities of geophysical instruments and the capability of new processing software to handle massive amounts of data should provide us with archaeogeophysical images with higher resolution than ever.

Looking deep into the history of coupling between geophysics and archaeology from its humble beginnings until today and having a glimpse at the foreseen future of this coupling allow us to say with confidence that the successful coupling between archaeology and geophysics is expected to get stronger in the near future.

\section{References}

1. Drahor MG (2006) Integrated geophysical studies in the upper part of Sardis archaeological site, Turkey. Journal of Applied Geophysics 59(3): 205-223.

2. Cardarelli E, Gerardina D (2009) Integrated geophysical method for characterization of an archaeological site (Massenzio Basilica- Roman forum, Roma, Italy). Journal of Applied Geophysics 68(4): 508-521.

3. Shaaban H, Qady EIG, Sayed AIE, Khozaym A, Emam AIA, et al. (2014) Archaeo-geophysical survey around Italy El-Baroud area, Nile Delta, Egypt. Archaeological Discovery 2(3): 45-57.

4. Dobecki T (2005) Geophysical exploration at the Giza Plateau, Egypt a ten-year odyssey. $18^{\text {th }}$ EEGS symposium on the application of geophysics to engineering and environmental problems: Exotic geophysics II, EEGS.

5. BeIshe J (1957) Recent magnetic investigations at Cambridge University. Advances in Physics 6(22): 192-193.

6. Aziz A, Sauck W, Shendi E, Rashed M, Abdel MA, et al. (2013) Application of analytic signal and Euler deconvolution in archaeo-magnetic prospection for buried ruins at the ancient city of Pelusium, NW Sinai, Egypt: A case study. Surveys in Geophysics 34(4): 395-411.

7. Dalan RA (1991) Defining archaeological features with electromagnetic surveys at the Cahokia Mounds State historic park. Geophysics 56(8): 1280-1287.

8. Hauck G, Guglielmin M, Isaksen K, Müuhll D (2001) Applicability of frequency domain and time-domain electromagnetic methods for mountain permafrost studies. Permafrost and Periglacial Processes 12(1): 39-52.

9. Rodrigues S, Porsani J, Santos V, Blasis DP, Giannini P, et al. (2009) GPR and inductive electromagnetic surveys applied in three coastal sambaqui (shell mounds) archaeological sites in Santa Catarina state, South Brazil. Journal of Archaeological Science 36(10): 2081-2088. 
10. Simpson D, Lehouck A, Verdonck L, Vermeersch H, Meirvenne M, et al (2009) Comparison between electromagnetic induction and fluxgate gradiometer measurements on the buried remains of a $17^{\text {th }}$ Century castle. Journal of Applied Geophysics 68(2): 294-300.

11. Foster E (1968) Further developments of the pulsed induction metal detector. Prospezioni Archeologiche 3: 95-99.

12. Tite M, Mullins C (1969) Electromagnetic prospecting- A preliminary investigation. Prospezioni Archeologiche 4: 95-102.

13. Leucci G, Negri S (2005) Use of ground penetrating radar to map subsurface archaeological features in an urban area. Journal of Archaeological Science 33(4): 502-512.

14. Sauck W, Smart L, Nassaney M, Porsani J (2006) Archaeological geophysics in an urban environment: peeling back the layers at Ft. Miami, Michigan. In: Proceedings of $19^{\text {th }}$ symposium on the application of geophysics to engineering and environmental problems (SAGEEP'2006), Seattle, USA, pp. 499-551.

15. Santos V, Porsani J, Mendonça C, Rodrigues S, Blasis DP, et al. (2009) Reduction of topography effect in inductive electromagnetic profiles: application on coastal sambaqui (shell mound) archaeological site in Santa Catarina state, Brazil. Journal of Archaeological Science 36(10): 2089-2095.

16. Zhao W, Forte E, Fontana F, Pipan M, Tiana G, et al. (2018) GPR imaging and characterization of ancient Roman ruins in the Aquileia Archaeological Park, NE Italy. Measurements 113: 161-171.

17. Eidt RC (1977) Detection and examination of anthrosols by phosphate analysis. Science 197(4311): 1327-1333.

18. Fajklewicz A, Glinski A, Sliz J (1982) Some applications of the underground tower gravity vertical gradient. Geophysics 47(12): 16881692.

19. Stright MJ (1986) Evaluation of archaeological site potential on the outer continental shelf using high-resolution seismic data. Geophysics 51(3): 605-622.

20. Forte E, Pipan M (2008) Integrated seismic tomography and groundpenetrating radar (GPR) for the high-resolution study of burial mounds (tumuli). Journal of Archaeological Science 35(9): 2614-2623. 